University of Nebraska - Lincoln

DigitalCommons@University of Nebraska - Lincoln

6-2001

\title{
The Response of Gregarina niphandrodes (Apicomplexa: Eugregarinida: Septatina) to Host Starvation in Tenebrio molitor (Coleoptera: Tenebrionidae) Adults
}

Jennifer E. Schawang

Oklahoma University Health Sciences Center

John J. Janovy Jr.

University of Nebraska - Lincoln, jjanovy1@unl.edu

Follow this and additional works at: https://digitalcommons.unl.edu/bioscijanovy

Part of the Parasitology Commons

Schawang, Jennifer E. and Janovy, John J. Jr., "The Response of Gregarina niphandrodes (Apicomplexa: Eugregarinida: Septatina) to Host Starvation in Tenebrio molitor (Coleoptera: Tenebrionidae) Adults" (2001). John Janovy Publications. 24.

https://digitalcommons.unl.edu/bioscijanovy/24

This Article is brought to you for free and open access by the Papers in the Biological Sciences at DigitalCommons@University of Nebraska - Lincoln. It has been accepted for inclusion in John Janovy Publications by an authorized administrator of DigitalCommons@University of Nebraska - Lincoln. 


\title{
THE RESPONSE OF GREGARINA NIPHANDRODES (APICOMPLEXA: EUGREGARINIDA: SEPTATINA) TO HOST STARVATION IN TENEBRIO MOLITOR (COLEOPTERA: TENEBRIONIDAE) ADULTS
}

\author{
Jennifer E. Schawang and J. Janovy, Jr. \\ School of Biological Sciences, University of Nebraska-Lincoln, Lincoln, Nebraska 68588-0118
}

\begin{abstract}
Numerous studies of host starvation have emphasized pathological effects of parasites on their insect host, but little attention has been focused on the effects of host starvation on the parasites. This study addressed the possibility that parasite life-cycle events could be manipulated by withholding food from the host. The system used was Gregarina niphandrodes (Apicomplexa: Eugregarinida) in Tenebrio molitor (Coleoptera: Tenebrionidae) adults. Gregarine gametocyst formation and shedding ceased after 1 day in starved beetles but continued in fed controls. There were no statistically significant differences between total lengths of associated ( 3 of 5 trials) or unassociated ( 5 of 5 trials) gregarines found between experimental and control groups, but average numbers of the 2 life cycle events were generally higher in fed hosts than in starved ones. If infected, fed control beetles continued to form gametocysts throughout the 7-day trial periods, and gametocysts could be observed in the gut. Starved experimental beetles had no gametocysts in their guts. Refeeding of starved beetles after 4 days resulted in resumption of gametocyst formation and shedding. The studies demonstrated that the gregarine life cycle could be stopped and then started at the gametocyst formation stage like an off/on switch, simply by withholding food from, then refeeding, the host.
\end{abstract}

Septate gregarines (Apicomplexa: Gregarinea: Eugregarinida: Septatina) are parasites primarily of arthropods and annelids. Gregarines have information-rich life cycles, in the sense that several stages can be measured and counted easily, trophont size varies with age, cells that will become macro- and microgamonts can often be distinguished prior to association, gamont association patterns vary between species, gametogenesis, fertilization, and subsequent oocyst formation all occur within gametocysts that vary structurally and in terms of dehiscence mechanisms, and finally, gregarine host/parasite relationships can be experimentally manipulated if the hosts can be cultured. In the conduct of experimental infections, gametocysts shed in the host feces must be collected, sometimes cleaned (depending on the study), and incubated under conditions that ensure oocyst development (sporulation) and release (dehiscence) (Clopton et al., 1992). In order to harvest gametocysts, hosts are typically placed in some kind of a slightly moist environment, e.g., a plastic shoebox with a paper towel and a few drops of water, without food for $24 \mathrm{hr}$. The moisture may be required by gametocysts during their first day of development, although gregarine species vary considerably in this respect, and the gametocysts of some species, evidently adapted to the arid environments of their hosts, require no moisture.

In the case of Tenebrio molitor, the yellow mealworm, adult beetles generally do not shed gametocysts after their first day in isolation, prompting a question concerning the life-cycle response of the parasites to host starvation. Septate gamonts of gregarines associate physically and then undergo syzygy, after which the paired gamonts secrete a gametocyst wall (Roberts and Janovy, 2000). Thus, cessation of shedding in response to host starvation could involve a number of parasite life-cycle events, including gamont association and cyst wall secretion. The objective of the present study was to establish which of these life-cycle events were affected by host starvation, and to determine whether the life cycle could be restarted by feeding after a period of starvation. The study was thus the first step toward discovering a specific physiological or biochemical re-

Received 8 August 2000; revised 8 October 2000; accepted 8 October 2000. lationship, between host and parasite, that ultimately allowed completion of a portion of the parasite's life cycle.

With one exception (Appel, 1983), other studies of host starvation and parasitic infections did not ask questions about effects on parasite life cycles but rather addressed pathogenicity to hosts, as defined by host death, declines in host nutrient stores, inability to pupate, and other similar measurements. For example, in observing host starvation in the T. molitor larvae and Gregarina polymorpha association, Harry (1967) concluded that infected T. molitor, when fed substandard diets, as opposed to enriched bran control diets, were not able to pupate and survived for shorter periods than hosts fed enriched diets. Several investigators demonstrated pathogenicity in the black carpet beetle Attagenus megatoma, infected with the eugregarine Pyxinia frenzeli, showing that starved hosts had diminished fat stores and exhibited weight loss (Dunkel and Boush, 1969; Schwalbe and Baker, 1976; Baker, 1977a, 1977b). However, these studies reported no effects on the parasites or their life cycles. In the one paper that addressed effects of host starvation on parasite biology, Appel (1983) observed that eugregarines displaced themselves posteriorly, and cyst formation also occurred posteriorly in the guts of starved Leucophaea maderae (Blattodea: Blaberidae). However, Appel (1983) did not report data from a control group, so no inferences could be made about how these positions deviate from those of parasites in fed roaches.

It is known that the intestinal environment changes with starvation in tenebrionid beetles. For example, in Tribolium castaneum, starvation resulted in large increases in intestinal amylase activity and surges in tissue cholesterol levels after 5-10 days, and declines in the levels of several other enzymes, such as acid and alkaline phosphatases (Saleem and Shakoori, 1986). These findings suggest that insect gut physiology could play a role in parasite life-cycle events, that this role may be altered experimentally by host starvation, and that the $T$. molitor $-G$. niphandrodes system eventually could be used to determine specific biochemical cues necessary for gametocyst formation in gregarine parasites.

Organism-level investigation of the effects of host starvation on parasite biology requires all parasite life-cycle events, at 
least those occurring within the insect host, to be observed, measured, and quantified. In the present study, an attempt was made to do this task systematically and completely, developing appropriate hypotheses for each component of the gregarine life cycle. Therefore, to explain absence of cyst shedding at the whole-organism level, the following null hypotheses were formed: (1) there is no difference in numbers of cysts shed by starved (experimental) and fed (control) hosts; (2) there is no difference in cyst formation between starved and fed hosts (rejection of this hypothesis would show that gametocysts are formed but retained in host guts possibly due to slowed bolus movement); (3) there is no difference in association patterns between parasites in starved and fed hosts (if gregarines are unable to associate, then syzygy, or cyst formation cannot occur); (4) there is no difference in sizes between parasites recovered from starved and fed hosts (size differences would indicate relatively different developmental rates under the different gut conditions); (5) there is no difference in the numbers of unassociated trophozoites examined in either starved or fed hosts (demonstration of differences in this particular life-cycle stage may indicate that host starvation causes parasite death); (6) there is no difference in sizes of unassociated trophozoites in either starved or fed hosts (observation of size of parasites asserts no differences in growth rates); and (7) there are no differences in cyst shedding between parasites of experimental and control hosts when experimental hosts are fed after a period of starvation (should there be absence of gametocyst shedding of starved hosts even after refeeding, then permanent arrest of the parasite life cycle may be assumed). Only through the testing of this set of hypotheses could it be determined which lifecycle events were actually halted by host starvation, and which events were unaffected by the experimental treatment.

\section{MATERIALS AND METHODS}

\section{Host and parasite maintenance}

All insects used in these studies were from $T$. molitor $\mathrm{L}$. stock colonies that have been maintained with commercial wheat bran and potatoes in large plastic sweater boxes for over $25 \mathrm{yr}$ at the University of Nebraska-Lincoln. Approximately $100 \mathrm{ml}$ of water was added to each colony 3 times a week. Gregarina species maintain themselves under these conditions in both larval and adult $T$. molitor through natural completion of the life cycle. Gregarina niphandrodes occurs only in the adult beetle, and adults are very rarely infected with small numbers of the larval parasite, Gregarina cuneata, that evidently do not complete development in the adult (Clopton et al., 1992); no other gregarine parasites occurred in the adult beetles used in these studies.

Gregarina niphandrodes is a species in which association occurs late in development, and the physically paired cells are usually very similar in size. For the purpose of this study, association is considered the criterion for transition into the gamont stage. Beetles were selected randomly from cultures without regard to age, sex, or reproductive status.

\section{Starvation trials}

Five time-zero control beetles were dissected from a source colony at the start of each trial, and their parasites were counted and measured. Starvation trials were conducted by placing 20 randomly chosen beetles with a moist paper towel into a clean plastic shoebox and covered with a lid. Twenty, nonstarved control beetles were placed in an identical plastic shoebox, under identical conditions, but fed enough wheat bran so that excess food was always available. The control group was placed in a clean empty shoebox on alternate days to collect gametocysts from host feces. Feces were collected daily from the starved group. Five beetles from each group were dissected on alternate days. Guts were removed, teased apart in Tenebrio muscle saline (Belton and Grundfest,
1962), and examined with a compound microscope under $40 \times$ and $100 \times$ magnification. All gregarines and gametocysts in the guts were counted, and protomerite and deutomerite lengths and widths were also measured. When infections were so heavy that all parasites could not be measured within $5 \mathrm{~min}$, the preparation was videotaped, measurements were made from the taped images, then converted to micrometers using screen calibration. Three of these 7-day trials were completed. The 7-day trial period (shorter than that required for the gregarine life cycle to be completed), combined with daily removal of feces, ensured that reinfection did not influence the results.

A second set of adult starvation trials was also run, except that groups of 20 beetles were isolated in individual plastic jars so that feces could be collected from all subjects on an individual basis. The plastic jars were covered with paper towels moistened lightly every day. Control beetles were each given a large, commercial cereal bran flake; experimental beetles were given nothing. Dissections were performed in the same manner as the trials using pooled subjects. Three such isolation trials, each lasting 7 days, were run.

\section{Refeeding experiments}

Forty beetles were divided into 2 groups. The experimental group was placed in a clean plastic shoebox with only a lightly moistened paper towel. The other group was individualized into clean plastic containers as in the isolation trials, and each beetle was provided with a large commercial wheat bran cereal flake. Feces were collected daily from all individuals and examined for gametocysts. On day 4, all starved (experimental) beetles were isolated in individual clean plastic containers, and each was provided a cereal flake. Feces were then collected from all beetles, both experimental and control, for 4 more days. On day 8 , beetles were dissected and their parasites measured and counted as previously described. Three trials were completed using this protocol. An additional 3 trials were performed as described, but the starved (experimental) beetles were isolated in individual plastic jars instead of being pooled in a shoebox. All beetles, when not being manipulated, were placed in an incubator set at a temperature of $28 \mathrm{C}$ and containing a pan of water that provided constant relative humidity of $82 \%$ (measured with VWR digital hygrometer/thermometer model 35519-048).

\section{Statistical analysis}

Counts and measurements in each experiment were analyzed using chi-squared tests, ANOVA, Mann-Whitney, and Wilcoxon tests (SAS $8.0,1999)$. Because the study design involved 2 different protocols (pooled and isolated), 2 treatment groups (starved and fed), and replicate trials in each protocol, 3-way ANOVAs were run on the mean lengths of both unassociated trophonts and associated gamonts and on mean numbers of trophonts and gamonts from each of these groups (Sokal and Rohlf, 1981). The tables give results from each experiment, mainly because such presentation provides a clearer picture of the way the $G$. niphandrodes $-T$. molitor system behaves under laboratory conditions, but 3-way ANOVA results also are given below in the text.

\section{RESULTS}

\section{Starvation trials}

The total numbers of gametocysts shed per trial in adult hosts under starved and fed conditions are shown in Table I. Gametocyst shedding was lower in starved adult hosts than in fed adult hosts. Furthermore, gametocyst shedding ceased after 12 days of starvation, but fed hosts continued to shed gametocysts if they were infected. Numbers of gametocysts recovered from dissected starved and fed adult beetles are shown in Table II. Gametocysts were nearly nonexistent in starved hosts, but fed hosts occasionally contained formed gametocysts that were ready to be passed in the host's feces. Usually, no gametocysts were collected from dissected starved hosts after day 1.

Average lengths of associated gamonts in starved and fed adult hosts are summarized in Table III. Gamonts in starved 
TABLE I. Comparisons of Gregarina niphandrodes total gametocysts shed in starved and fed adult hosts; all statistics had 1 degree of freedom.

\begin{tabular}{lcccc}
\hline \multicolumn{1}{c}{ Trial } & Starved & Fed & $\chi^{2}$ value & $P_{\text {equality }}$ \\
\hline Pooled adult data & & & & \\
$\quad$ Trial 1 & 4 & 49 & 38.20 & $<0.001$ \\
Trial 2 & 0 & 42 & 42.00 & $<0.001$ \\
Trial 3 & 0 & 32 & 32.00 & $<0.001$ \\
Isolated adult data & & & & \\
Trial 1 & 0 & 6 & 6.00 & $<0.050$ \\
Trial 2 & 0 & 14 & 14.00 & $<0.001$ \\
Trial 3 & 1 & 87 & 84.04 & $<0.001$ \\
\hline
\end{tabular}

beetles were longer than gamonts in fed hosts in 5 of 6 trials, but only 1 of the 6 trials yielded statistically significantly different results. Three-way ANOVA revealed neither significant main effects $\left(F_{\text {pooled vs. isolated }}=6.04[1,2], F_{\text {trial no. }}=2.23[2,2]\right.$, $\left.F_{\text {starved vs. fed }}=0.24[1,2]\right)$ nor first-order interactions $\left(F_{\text {pooled vs. }}\right.$ trial $=1.11[2,2] ; F_{\text {pooled vs. starvation }}=0.77[1,2] ; F_{\text {trial vs. starvation }}=$ $2.45[2,2] ; P$ in all cases $>0.05)$.

Table IV shows the average numbers of associated gamonts per beetle, the life-cycle development stage that occurs prior to syzygy. The numbers of associated gamonts were always larger in fed hosts than in starved hosts, but these differences were significant in only 2 of 6 trials when tested by ANOVA and in 1 of the 6 trials when tested by Wilcoxon. Three-way ANOVA revealed neither main effects $\left(F_{\text {pooled vs isolated }}=0.75[1,2], F_{\text {trial no }}\right.$ $\left.=0.23[2,2], F_{\text {starved vs. fed }}=4.99[1,2]\right)$ nor significant first-order interactions $\left(\mathrm{F}_{\text {pooled vs. trial }}=2.92[2,2] ; \mathrm{F}_{\text {pooled vs. starvation }}=4.94[1\right.$, $2] ; \mathrm{F}_{\text {trial vs. starvation }}=1.66[2,2] ; P$ in all cases $\left.>0.05\right)$.

The average lengths of unassociated $G$. niphandrodes trophonts are compared in Table V. In 2 of 6 trials, starved hosts had significantly larger unassociated trophonts than fed hosts, and in another 2 trials, fed beetles had significantly larger unassociated trophonts than starved beetles. In the 2 trials that yielded no significant differences between treatments, average trophont lengths between the 2 treatment groups were nearly equal. Three-way ANOVA revealed no significant main effects $\left(F_{\text {pooled vs. isolated }}=0.03[1,2], F_{\text {trial no. }}=3.58[2,2], F_{\text {starved vs. fed }}=\right.$ $0.99[1,2])$ or first-order interactions $\left(\mathrm{F}_{\text {pooled vs. trial }}=0.49[2,2]\right.$; $\mathrm{F}_{\text {pooled vs. starvation }}=4.02[1,2] ; \mathrm{F}_{\text {trial vs. starvation }}=4.95[2,2] ; P$ in all cases $>0.05$ ). No exceptionally large or robust unpaired tro-

TABLE II. Comparisons of Gregarina niphandrodes total gametocysts retained in the guts of starved and fed adult hosts; all statistics had degree of freedom.

\begin{tabular}{lcrcc}
\hline \multicolumn{1}{c}{ Trial } & Starved & Fed & $\chi^{2}$ value & $P_{\text {equality }}$ \\
\hline Pooled adult data & & & & \\
$\quad$ Trial 1 & 0 & 16 & 16.00 & $<0.001$ \\
Trial 2 & 3 & 11 & 2.29 & NS \\
Trial 3 & 0 & 5 & 5.00 & $<0.050$ \\
Isolated adult data & & & & \\
Trial 1 & 0 & 1 & 1.00 & NS \\
Trial 2 & 0 & 0 & 0.00 & NS \\
Trial 3 & 1 & 4 & 1.80 & NS \\
\hline
\end{tabular}

TABLE III. Comparisons of lengths of associated Gregarina niphandrodes gamonts in starved and fed adult hosts.

\begin{tabular}{lccccc}
\hline \multicolumn{1}{c}{ Trial } & $\begin{array}{c}\text { Starved } \\
(\mu \mathrm{m})\end{array}$ & $\begin{array}{c}\text { Fed } \\
(\mu \mathrm{m})\end{array}$ & $\begin{array}{c}\text { ANOVA } \\
F \text {-value }\end{array}$ & df & $P_{\text {equality }}$ \\
\hline Pooled adult data & & & & & \\
$\quad$ Trial 1 & 671.08 & 629.96 & 4.58 & 1,48 & $<0.05$ \\
Trial 2 & 729.60 & 680.04 & 0.73 & 1,49 & NS \\
Trial 3 & 643.20 & 633.38 & 0.07 & 1,11 & NS \\
Isolated adult data & & & & & \\
$\quad$ Trial 1 & 473.60 & 226.40 & 7.03 & 1,4 & NS \\
Trial 2 & 700.80 & 721.64 & 0.18 & 1,21 & NS \\
Trial 3 & 473.60 & 463.84 & 0.10 & 1,34 & NS \\
\hline
\end{tabular}

phonts or aberrant forms were observed in any of the starved beetles.

Table VI shows the average numbers of unassociated trophonts per host. Although 5 of 6 trials show that the numbers of unassociated trophonts were greater in fed hosts than in starved hosts, in none of the 6 trials were the differences statistically significant when tested by either ANOVA or Wilcoxon. Three-way ANOVA revealed both significant main effects of trial number and starvation $\left(F_{\text {pooled vs. isolated }}=4.94[1,2], F_{\text {trial no. }}=30.15[2,2], F_{\text {starved }}\right.$ vs. fed $=133.40[1,2])$, and first-order interactions depending on whether beetles were pooled or isolated $\left(\mathrm{F}_{\text {pooled vs. trial }}=177.29[2\right.$, $\left.2] ; \mathrm{F}_{\text {pooled vs. starvation }}=404.39[1,2]\right)$, but no first-order interactions were evident between trials $\left(\mathrm{F}_{\text {trial vs. starvation }}=4.95[2,2]\right)$.

\section{Refeeding exercises}

Figures 1 and 2 show the total gametocysts shed per day in each trial from all pooled, then isolated beetles that were starved for 4 days, then fed for 4 days, and the control group, respectively. Figures 3 and 4 show the total gametocysts shed per day in each trial from isolated starved, then refed beetles, and the control beetles, respectively. These data show that gametocyst shedding stopped during starvation periods but then started following refeeding. In comparing the total numbers of gametocysts shed, fed hosts shed more gametocysts overall than did starved hosts; the statistics for the comparisons of gametocysts shed among groups are summarized in Table VII.

TABLE IV. Comparisons of average numbers of associated Gregarina niphandrodes gamonts per beetle in starved and fed adult hosts.

\begin{tabular}{lccccc}
\hline \multicolumn{1}{c}{ Trial } & Starved & Fed & $\begin{array}{c}\text { ANOVA } \\
F \text {-value }\end{array}$ & df & $P_{\text {equality }}$ \\
\hline Pooled adult data & & & & & \\
$\quad$ Trial 1 & 1.65 & 1.78 & 0.01 & 1,36 & $\mathrm{NS}$ \\
$\quad$ Trial 2* & 0.16 & 2.17 & 4.43 & 1,40 & $<0.05$ \\
$\quad$ Trial 3 & 0.33 & 0.60 & 0.60 & 1,20 & $\mathrm{NS}$ \\
Isolated adult data & & & & & \\
$\quad$ Trial 1 & 0.16 & 0.18 & 0.02 & 1,34 & $\mathrm{NS}$ \\
Trial 2* & 0.05 & 1.40 & 6.55 & 1,38 & $<0.05$ \\
Trial 3 & 1.70 & 4.79 & 1.87 & 1,22 & $\mathrm{NS}$ \\
\hline
\end{tabular}


TABLE V. Comparisons of lengths of unassociated Gregarina niphandrodes trophonts in starved and fed adult hosts.

\begin{tabular}{lcrrrc}
\hline \multicolumn{1}{c}{ Trial } & $\begin{array}{c}\text { Starved } \\
(\mu \mathrm{m})\end{array}$ & $\begin{array}{c}\text { Fed } \\
(\mu \mathrm{m})\end{array}$ & $\begin{array}{c}\text { ANOVA } \\
F \text {-value }\end{array}$ & df & $P_{\text {equality }}$ \\
\hline Pooled adult data & & & & & \\
$\quad$ Trial 1 & 269.88 & 221.41 & 47.41 & 1,557 & $<0.001$ \\
$\quad$ Trial 2 & 246.05 & 246.84 & 0.03 & 1,959 & $\mathrm{NS}$ \\
$\quad$ Trial 3 & 197.59 & 224.20 & 9.46 & 1,417 & $<0.005$ \\
Isolated adult data & & & & & \\
$\quad$ Trial 1 & 182.33 & 191.86 & 0.70 & 1,236 & $\mathrm{NS}$ \\
Trial 2 & 240.53 & 306.49 & 153.76 & 1,848 & $<0.001$ \\
Trial 3 & 189.41 & 175.38 & 4.60 & 1,470 & $<0.050$ \\
\hline
\end{tabular}

\section{DISCUSSION}

The major contribution of the present study is the demonstration that in the $G$. niphandrodes-T. molitor system, a parasite's life cycle can be turned off, then turned on again, as if controlled by a physiological switch, simply by withholding food from the host. A second contribution is the demonstration that gametocyst formation is evidently the only stage significantly affected by host starvation, although there is some evidence that trophonts did not survive as well in starved hosts as in fed ones. A third contribution is the demonstration that neither surviving trophont nor gamont growth is affected by host starvation. This conclusion is supported by lack of consistent significant differences in sizes of trophonts or gamonts in starved and fed hosts, as well as the observation that gametocysts continue to be formed and can be found in the guts of fed hosts but not in starved hosts. A final contribution is the demonstration that gametocyst formation resumes immediately upon refeeding. Clearly, there is some cue, derived either directly or indirectly from the host's diet that is detected by the parasite or a gametocyst-specific biochemical or physiological requirement provided by a bran flake that allows resumption of the parasite's life cycle.

The observations are presented as a series of tables giving the results of each trial because this mode of presentation best reflects the actual observations. In theory, it is possible to standardize hosts in terms of age, sex, virginity, exposure to oocysts, etc., so that trial-to-trial variation is minimized, but in

TABLE VI. Comparisons of average numbers of unassociated Gregarina niphandrodes trophonts per beetle in starved and fed adult hosts.

\begin{tabular}{lcrccc}
\hline \multicolumn{1}{c}{ Trial } & Starved & Fed & $\begin{array}{c}\text { ANOVA } \\
F \text {-value }\end{array}$ & df & $P_{\text {equality }}$ \\
\hline Pooled adult data & & & & & \\
$\quad$ Trial 1 & 19.30 & 11.11 & 2.39 & 1,36 & NS \\
Trial 2 & 18.60 & 23.48 & 0.21 & 1,39 & NS \\
Trial 3 & 15.08 & 26.00 & 1.74 & 1,20 & NS \\
Isolated adult data & & & & & \\
$\quad$ Trial 1 & 4.26 & 9.44 & 1.28 & 1,35 & NS \\
Trial 2 & 19.28 & 28.65 & 0.95 & 1,36 & NS \\
Trial 3 & 26.60 & 40.36 & 0.30 & 1,22 & NS \\
\hline
\end{tabular}

* Wilcoxon tests indicated that in none of the trials were the differences in numbers between control and experimental groups statistically significant.

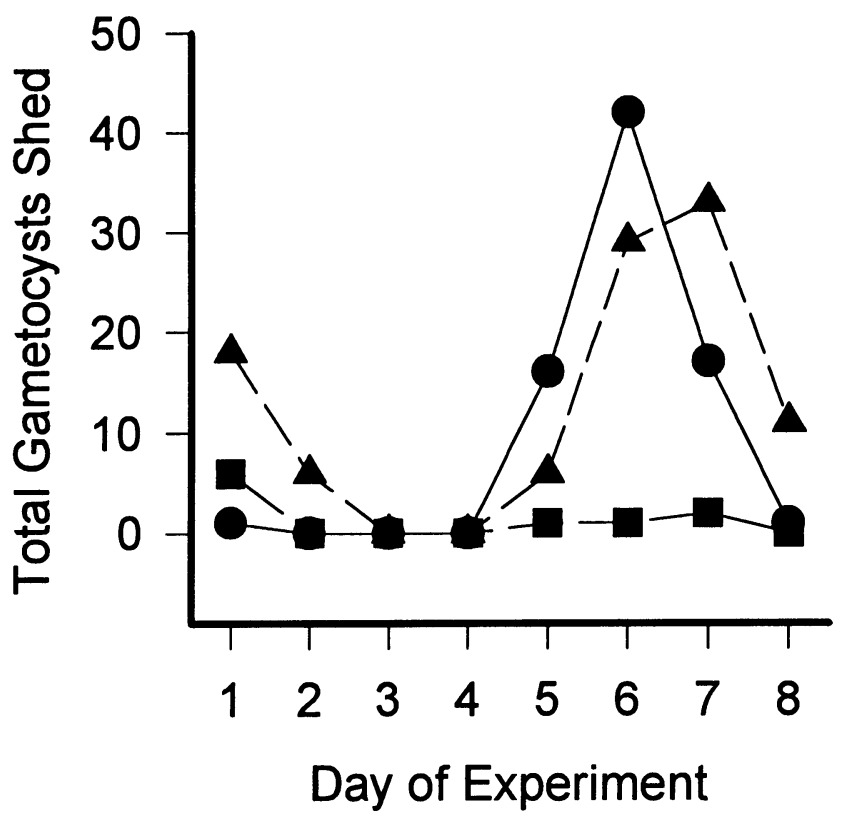

FIGURE 1. Gametocyst shedding as a result of feeding pooled adult Tenebrio molitor after a period of starvation. Circles, trial 1; squares, trial 2; triangles, trial 3.

practice this effort consumes vast amounts of time and space, especially when large numbers of hosts are required on schedule, and even with this kind of effort, one cannot ensure that each individual beetle consumes roughly an equivalent number of oocysts. Anecdotal evidence indicates that postmetamorphosis time clearly affects the probability that a beetle will be infected, but in the course of dissecting numerous beetles from several colonies, one periodically encounters heavily infected, light-colored, nongravid, i.e., relatively young, as well as non-

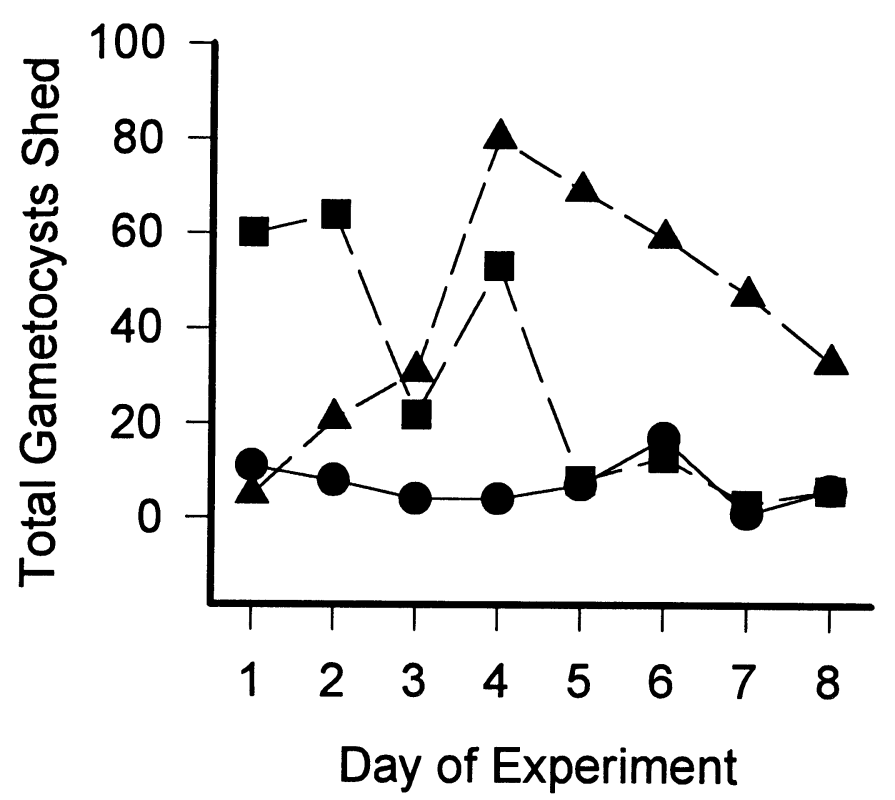

FIGURE 2. Gametocyst shedding from pooled control (continuously feeding) adult Tenebrio molitor. Circles, trial 1; squares, trial 2; triangles, trial 3. 


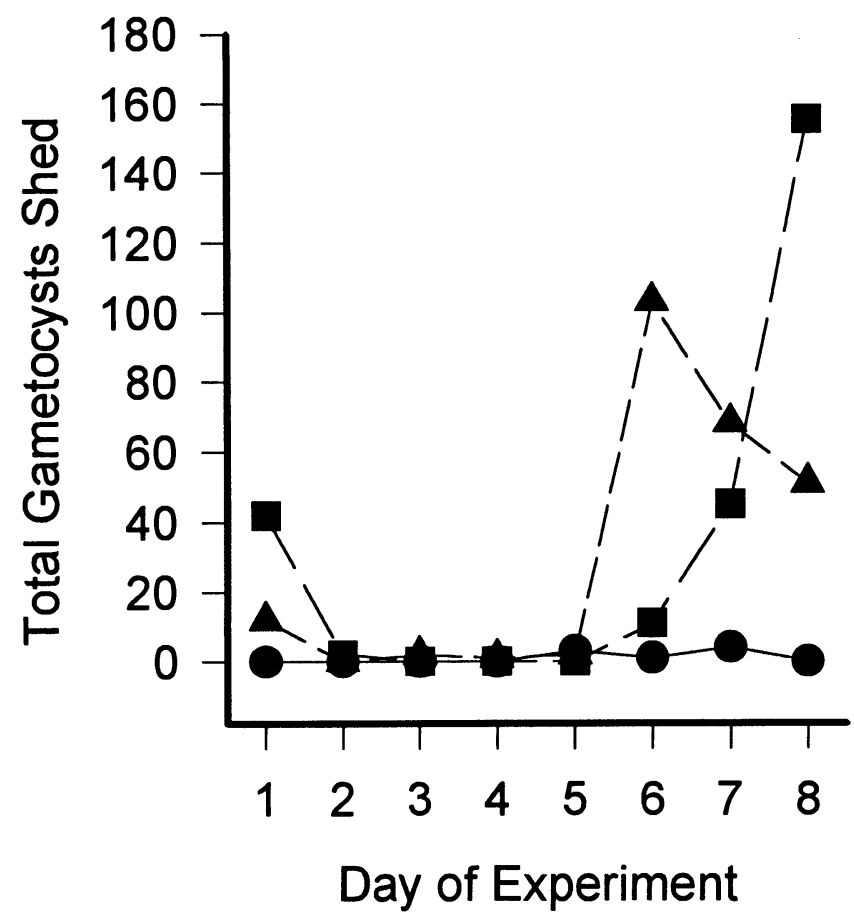

FIGURE 3. Gametocyst shedding as a result of feeding isolated adult Tenebrio molitor after a period of starvation. Circles, trial 1; squares, trial 2; triangles, trial 3 .

infected, very dark, i.e., relatively old, quite gravid, females. It is obvious from such dissections that beetles sometimes encounter, then consume, a mass of oocysts, possibly resulting from a single dehisced gametocyst or a single spore chain, and that beetles may also either be resistant to infection or simply fail to eat any oocysts for much of their life. Given that so many variables simply cannot be controlled, one must look for repeated patterns and consistency of results.

The 3-way ANOVAs tend to confirm what the tables show, namely, that starvation does not predictably affect trophont or gamont growth. Both trophont and gamont numbers, however, evidently are reduced by host starvation. Although none of the 6 experiments showed significant trophont number differences when analyzed individually, the 3-way ANOVA showed a significant starvation treatment effects. with fed beetles having more parasites in 5 of the 6 trials. Similarly, gamont numbers were consistently, but not always significantly, lower in starved hosts than in fed ones (Table IV). Although majority rules is not an appropriate statistical criterion in any case, the results do suggest that some parasites either die when the host is starved or are unable to maintain their position in the gut and are passed in the feces.

This study raises a number of questions that could be addressed in future studies, particularly with respect to host age, sex, and reproductive status, all of which potentially influence the host-parasite relationship (von Brand, 1979). But among these questions, the one regarding the off/on switch of gametocysts is perhaps of most evolutionary significance. The gametocyst is unique to gregarines, and within that cyst, both oocyst development and dehiscence are complex processes that vary considerably according to taxon. Because the gametocyst is shed in the feces, and the environment encountered during

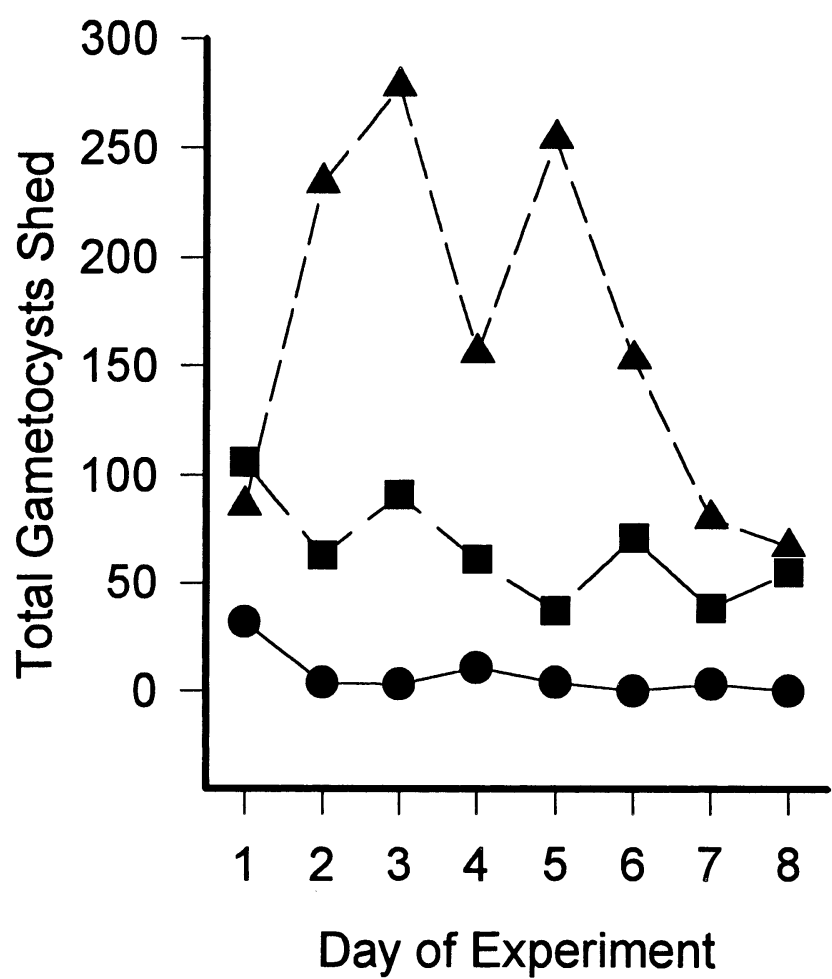

FIGURE 4. Gametocyst shedding from isolated control (continuously feeding) adult Tenebrio molitor. Circles, trial 1; squares, trial 2; triangles, trial 3.

TABLE VII. Statistical analysis of gametocyst shedding results from refeeding experiments shown in Figures 1-4.*

\begin{tabular}{|c|c|c|c|c|c|}
\hline \multirow[b]{2}{*}{ Trial } & \multicolumn{4}{|c|}{ Comparisons made in cyst shedding } & \multirow[b]{2}{*}{ df } \\
\hline & $\begin{array}{c}\text { Total } \\
\text { cysts per } \\
\text { trial } \dagger\end{array}$ & $\begin{array}{c}\text { Days } 1-4 \\
\text { control } \\
\text { vs. } \\
\text { experi- } \\
\text { mental } \dagger\end{array}$ & $\begin{array}{c}\text { Control } \\
\text { days } 1-4 \\
\text { vs. } \\
\text { days } 1-5 \dagger\end{array}$ & $\begin{array}{l}\text { Cysts shed } \\
\text { in same } \\
\text { experi- } \\
\text { mental } \\
\text { hosts } \\
\text { days } 1-4 \\
\text { vs. } 5-8 \ddagger\end{array}$ & \\
\hline \multicolumn{6}{|c|}{ Pooled adult data } \\
\hline Trial 1 & $4.76 \S$ & $24.14 \|$ & $28.51 \|$ & N/A & 1 \\
\hline Trial 2 & $200.68 \|$ & $181.70 \|$ & $187.32 \|$ & N/A & 1 \\
\hline Trial 3 & $134.68 \|$ & $79.31 \|$ & $15.57 \|$ & N/A & 1 \\
\hline \multicolumn{6}{|c|}{ Isolated adult data } \\
\hline Trial 1 & $36.94 \|$ & $50.00 \|$ & $30.41 \|$ & $2.50 \S$ & 21 \\
\hline Trial 2 & $91.75 \|$ & $210.22 \|$ & $22.74 \|$ & $2.43 \S$ & 16 \\
\hline Trial 3 & $738.70 \|$ & $710.17 \|$ & $298.98 \|$ & $1.13(\mathrm{~ns}) \#$ & 9 \\
\hline
\end{tabular}

* Table entries for pooled data are $\chi^{2}$ values, for individualized data are paired $t$ values. Days 1-4 were the starvation period; days 5-8 were the feeding period. $\dagger$ The test statistic was $\chi^{2}$ with 1 degree of freedom.

$\ddagger$ The test statistic was paired $t$.

$\S P<0.05$.

$\| P<0.001$.

\# Differences were not statistically significant. 
the first $24 \mathrm{hr}$ is evidently of great importance to subsequent oocyst development (Clopton and Janovy, 1993), this switch is likely an important component of the adaptation of the parasite not only to its host, but to the ecological niche of its host species.

\section{ACKNOWLEDGMENTS}

This work was conducted in part at the Cedar Point Biological Station and was supported in part by an Ashton C. Cuckler scholarship to J.E.S. from the University of Nebraska-Lincoln.

\section{LITERATURE CITED}

APPEL, A. G. 1983. Distribution and cyst formation of Gregarina rhyparobiae Watson as a response to host starvation. Journal of Parasitology 69: 424-425.

BAKER, J. E. 1977a. Factors affecting pupation of starved larvae of the black carpet beetle, Attagenus megatoma. Journal of the Georgia Entomological Society 12: 268-272.

. 1977b. Synchronized pupation in starved and fed larvae of the black carpet beetle. Annals of the Entomological Society of America 70: 299-302.

Belton, P., AND H. Grundfest. 1962. Potassium activation and K spikes in muscle fibers of the mealworm larva (Tenebrio molitor). American Journal of Physiology 203: 588-594.

Clopton, R. E., AND J. JANOvy, JR. 1993. Developmental niche structure in the gregarine assemblage parasitizing Tenebrio molitor. Journal of Parasitology 79: 701-709.

- —, AND T. J. Percival. 1992. Host stadium specificity in the gregarine assemblage parasitizing Tenebrio molitor. Journal of Parasitology 78: 334-337.

DunKel, F. V., AND G. M. Boush. 1969. Effect of starvation on the black carpet beetle, Attagenus megatoma, infected with the eugregarine Pyxinia frenzeli. Journal of Invertebrate Pathology 14: 4952.

HARRY, O. G. 1967. The effect of a eugregarine Gregarina polymorpha (Hammerschmidt) on the mealworm larva of Tenebrio molitor (L.). Journal of Protozoology 14: 539-547.

Roberts, L. S., AND J. JANOVY, JR. 2000. Gerald D. Schmidt and Larry Roberts' foundations of parasitology, 6th ed. McGraw-Hill Company, Inc., Dubuque, Iowa, 670 p.

SAS INSTITUTE. 1999. JMP statistical software package, version 8.0. Cary, North Carolina.

SAlEEM, M., AND A. R. SHAKOORI. 1986. Starvation and refeeding in Tribolium castaneum (Herbst). I. Effect on some biochemical components of sixth instar larvae. Canadian Journal of Zoology 64: $1628-1632$.

Schwalbe, C. P., AND J. E. BAKer. 1976. Nutrient reserves in starving black carpet beetle larvae infected with the eugregarine Pyzinia frenzeli. Journal of Invertebrate Pathology 28: 11-15.

SoKAl, R. R., AND F. J. Rohlf. 1981. Biometry, 2nd ed. W. H. Freeman and Company, New York, New York, 859 p.

VON BRAND, T. 1979. Biochemistry and physiology of endoparasites. Elsevier/North Holland Biomedical Press, New York, New York, 447 p. 